\title{
Turn Taking of Conversation (A Case Study of Marhata in Traditional Wedding Ceremony of Batak Toba)
}

\author{
Selviana Napitupulu ${ }^{1}$, Sanggam Siahaan ${ }^{2}$ \\ ${ }^{l}$ (Universitas HKBP Nommensen, Medan-Pematangsiantar, Indonesia) \\ ${ }^{2}$ (Universitas HKBP Nommensen, Medan-Pematangsiantar, Indonesia)
}

\begin{abstract}
This research aims to formulate the pattern of turn-taking of conversation in traditional wedding ceremony in three speech situations. This research applies descriptive qualitative method. Field data, documentation and direct observation were carried out. The content of the utterances containing turn taking was verified to the expert of marhata. The analysis was based on the content and sequence to find the recurring patterns using conversation analysis approach. The research findings showed that the three rules of turn taking were applicable. Yet, the first rule was more dominant in every speech situation. It referred to the reference of kinship and the use of pronoun. When the speaker from the man's side gave turn taking to the woman's side, addresses system was used as a reference to the speaker of the woman's side while the speaker from the woman's side used personal pronoun to give turn to the man's side.
\end{abstract}

Keywords: marhata, ceremony, turn taking, conversation analysis, Batak Toba traditional wedding

\section{Introduction}

Batak Toba ethnics never release from the traditional ceremony. One of the most important things from the traditional ceremony is marhata commonly conducted by the speakers. In Batak Toba ethnics, someone will be highly appreciated if he is able to perform oral communication well, especially in marhata 'conversation on traditions'. The success of marhata in Batak Toba traditional ceremony is more dominantly determined by the speakers. The wedding traditional ceremony is the largest traditional ceremony in the Batak Toba ethnics.

Being a successful and appreciated speaker in traditional ceremony especially in a marhata has some characteristics; he must have competence at speaking; understand the values of marhata containing some socialcultural ones; have readiness to be appointed by the relatives to be a speaker in a whole day and willingness or motivation.

Most of the Batak Toba lost the ability of marhata. Human resource acting as a speaker in marhata is very small compared with the majority of the society. The large number of the Batak society is not balanced with the society who has competence as a speaker in marhata. Many old generations are unable to converse in tradition conversation called marhata, even as an experienced speaker himself is still not able professionally mastering marhata.

One of the approaches in analyzing conversation is conversation analysis (CA), which emerged in the pioneering researches of Harvey Sacks (Hutchby, 1998: 5) into the structural organization of everyday language use, accounted by his friend Schegloff (Have, 1999:5). Sacks (Hutchby and Woffit, 1999:18) had observed that in the majority of cases if the person is taking the call within the organization started off by giving their name, then the suicidal person who was calling would be likely to give their name in reply. But in one particular call, he noticed that the caller (B) as shown in the conversation above seemed to be having trouble with the name of the answerer. Then the agent who took the call found it difficult to get the caller's name. For him, the avoidance of giving one's name in the conversation by answering "I can't hear you" leads to the accomplishment of action or particular things given by an utterance. So, in this case the utterance is an action.

However, Sacks (Hutchby and Woffit, 1998:8) here emphasizes that "I can't hear you" is not always an expression representing the way one avoids giving his name. Rather he viewed the utterance as an action which is situated within specific context. He also observed that by the caller's "not hearing", he is able to set up a sequential trajectory in which the agent finds less opportunity to establish the caller's name without explicitly asking for it. Thereby the caller is able to begin the conversation by avoiding giving a name without actually refusing to do so. Utterance as an action is also supported by Schegloff $(2007: 1)$ as he focused on action rather 
than a topic in talk-in interaction. An utterance like "Would somebody like some more ice tea?" is better understood as "doing an offer" than as "about ice tea".

The formal aspects of conversation are how the turn taking works; the rules to obey; how the sequencing can be achieved (give and get turn taking ) or the mechnism of turn-taking, interuption, overlap, etc). This paper is much talking about rules of turn-taking applied in marhata of Batak Toba traditional wedding ceremony based on CA analysis.

In accordance with the background presented above, the statement of the research problem explored in this study is 'How is the pattern of turn taking marhata in Batak Toba traditional wedding ceremony applied?'

In congruence with the research problem stated, the statement of the research objective explored in this study is to formulate the pattern of turn taking marhata in Batak Toba traditional wedding ceremony.

Theoretically the findings of this research can be very essential information for developing the theory of turn taking in local language in Indonesia. Practically, the findings can also be applicable information for the speakers of Batak Toba to use the pattern of turn taking when they make conversation on traditions. Besides, the findings can be necessary information for the young generation in order to improve their competence in participating in a conversation of tradition. In addition, the findings can be very significant for the whole Batak Toba society to understand the meanings of the turn taking.

\subsection{Communicative Competence}

\section{Related Literature}

The history of linguistic competence is initiated by the structural linguist. The term, according to Chomsky (1957), is the unconscious knowledge of the native speakers on the linguistic rules of their language. It is said that this knowledge governs them to produce and interpreted the linguistic aspects, such as the phonological aspects, the morphological aspects, and the syntactic aspects of their language. However, in the development of the term to become communicative competence, it is argued that the term competence is quite restricted to the pure linguistic aspects of a language which is isolated from the context of communication. Such a term excludes paralinguistic aspects which are so necessary to consider in creating and interpreting a communicative meaning in order to make a certain function and effect on both sides of the speakers and the listeners in a communicative interaction. So it is always argued that the term competence refers to the unconscious knowledge on the mere linguistic aspects of a language; the knowledge is argued only a part of the perfect one needed by the speakers of a language to take part in a communicative interaction.

Communicative competence refers to the unconscious knowledge of the native speakers of a language on both the linguistic rules and the paralinguistic rules of the language. Hymes (1972) says that in addition to the ability in recognizing the linguistic aspects which are available to them, communicative competence also refers to the ability of the native speakers of a language to recognize the other aspects, they are the suprasentential structuring, the rule of interpretation, and the norm which govern different types of interaction. The concept of communicative competence elaborated by Hymes does not only cover the linguistic knowledge, but it also covers the knowledge on the contextual aspects in which the linguistic aspects can have function in the communication of a meaning. Now the communicative competence of the native speakers of a language is seen from the angle of the ability of the native speakers of a language to as fully as possibly exploit the linguistic features in both the linguistic feature and the paralinguistic features as contexts or as fully as possibly exploit both the linguistic features and the paralinguistic features for the context of the linguistic features. In short, it can be argued that the term communicative competence refers to the unconscious knowledge of the native speakers of a language which enable them to use both the linguistic and paralinguistic features which are resourceful to them to participate in a social communicative interaction in the daily life.

\subsection{Conversation Analysis}

Conversation Analysis is derived from Ethnomethodology which is focused on the methods by which the group conducts conversation. Group here refers to society's members which are considered having intersubjectivity and common-sense knowledge realized in talk-in interaction in their daily life. Obviously, the member's knowledge meant by this method concerns with the member's knowledge of their ordinary affairs, knowledge that shows a sense of order in everyday conduct, and this is publicly displayed in activity which is going on.

Of Sacks' observation on talk-in interaction (Hutchby et.al, 1999), he really based his analysis on the naturally occurring data from which he did a turn by turn detail of the conversation so that a robust analytical basis would be used to get a robust finding. What he observed then leads to the key insights which are treated on the methodological basis for conversation analysis. These key insights can be summarized below:

1. Talk - in interaction is systematically organized and deeply ordered.

2. The production of talk - in interaction is methodical.

3. The analysis of talk- in interaction should be based on naturally occurring data. 
4. Analysis should not be constrained by prior theoretical assumption.

Hutchby and Wooffitt (2008) say that conversation analysis is a study on how the participants of a conversation organize their contribution in the conversation. The focus in this concept is to give a contribution in a conversation. Giving a contribution in a conversation deals with how to start, continue, and end the conversation. In a natural conversation, it is indicated that a participant can use some linguistic features or even non-linguistic features which function as markers in order to signal that a participant is going to take a turn or to signal that she or he is still continuing the turn or to signal that a participant is going to pass the turn.

\subsection{Turn -Taking}

In everyday talk, there are no formal rules, about who can talk, when and about what, rather who gets a turn in a conversation. Turn-taking is the process through which the party doing the talk of the moment is changed. The definition implies that there is a process in turn - taking, that is a process of speaker changes. If it is a process of speaker changes, then there would be patterns from the recursive process.

Sacks, Schegloff, and Jafferson (1974:706) presented fourteen recurring patterns of turn taking in English:

1. Speaker change recurs, or at least occurs.

2. Overwhelmingly, one party talks at a time.

3. Occurrences of more than one speaker at a time are common, but brief.

4. Transition (from turn to a next), with no gap and no overlap are common. Together with a transitions characterized by slight gap or slight overlap, they make up the vast majority of transition.

5. Turn order is not fixed, but varies

6. Turn size is not fixed, but varies

7. Length of conversation is not specified in advance

8. What parties say is not specified in advance.

9. Relative distribution of turns is not specified in advance.

10. Number of parties can vary.

11. Talk can be continuous or discontinuous.

12. Turn allocation techniques are obviously used. A current speaker may select a next speaker (as when he addresses a question to another party): or parties may self -select in starting to talk.

13. Various turn - constructional units are employed; e.g. turns can be projected one word long or they can be sentential in length.

14. Repair mechanisms exist for dealing with turn - taking errors and violations, e.g. if two parties find themselvess talking at the same time, one of them will stop prematurely, thus repairing the trouble.

\subsection{Turn Construction Units (TCU)}

There are two kinds of understanding of turn in conversation, they are mechanical and interactional. It is mechanical when turns are treated as units of talk in interaction and exclude any interpretation that regards social context. The basic units of utterance are considered as turn construction units (TCU). They are units that develop turn, and the types vary, such as, sentence, clause, phrase, or word. Turns also can be seen as an end boundary marked by turn claiming responses by participants. So turns in this sense refers to both utterances divided by speaker's changes as well as opportunities for the speaker to take turn in interaction. In other words, turns are composed of TCU and transition relevance place (TRP) at the end of TCU.

Interactional understanding of turn refers to exchange of speaker roles in interaction. Turn is an opportunity to hold the floor, not what is said while holding it. Turns here concern the speaker's right or obligation to talk, as well as the concept of floor- who has the privilege to hold the floor. The distinction between mechanical and interactional approaches is somewhat similar to that between system constraints and ritual constraints that affect turn-taking. System constraint is parallel to mechanical approach, that is, dealing with turn sequences are managed, like how the next speaker selected. So it is not considered to be influenced by social context. Ritual constraints vary from situation to situation and from culture to culture. Speakers are viewed in relation to others in social sense. So turns are also determined by cultural context.

\subsection{Turn Allocation Component}

Getting a turn can be a serious issue especially in ordinary conversation. In our life we always have mechanisms to organize our activities by applying sequential or alternating turns. Football watchers buy tickets in sequence determined by the individual's position in line. The first position in line is the first who gets the ticket. They queue based on the rule issued to them. To get a turn is an important thing that many people try to arrive hours or days ahead of time to ensure a place in line. This system operates single turn, that is, one person at a time regardless of whether he buys more than one tickets though in some cases number of tickets are 
restricted. The other turn system can deal with one that allows all participants to take the turns at the same time as shown in guests having dinner party. In conversation it is important to have single sequential turns as human beings limited capacity to cope with several different spoken messages at once.

People who talk in daily life may need to be the very next person to speak but even they desperately have an effort to do it they are difficult to get a word in edgewise. Unlike in institutional talk such as in seminar, debate or in tradition ceremony of wedding in Batak Toba setting, who talks, when, how, have been predetermined or pre-specified before. Sometimes it depends on the speaker status. In daily conversation turns are locally and interactionally managed. Locally managed means that the participants themselves determine who shall speak next, including turn size, turn length, number of parties, and what parties say. Turn allocation is not determined before participants begin. Interactionally managed means that one participant affects what the others may acceptably do, that is, if the current speaker chooses who speaks next, the chance to other speakers is reduced. This is a participant-managed turn system.

How are turns allocated among participants? The following are basic set of rules for determining who gets the next turn, as shown below.

1) For any turn, at the initial transition-relevance place of an initial turn construction unit:

a) If the turn so far is constructed as to involve the use of a 'current speaker selects next' technique, then the party so selected has the right and is obliged to take next turn to speak; no others have such rights or obligation, and transfer occurs at the place.

b) If the turn so far is constructed as not to involve the use of a 'current speaker selects next' technique, then self-selection for next speakership may, but need not, be instituted; first starter acquires rights to turn, and transfer occurs at that place.

c) If the turn so far is constructed as not to involve the use of a 'current speaker selects next' technique, then current speaker may, but need not continue, unless another self selects.

2) If, at the initial transition-relevance place of an initial turn-construction unit, neither 1a nor 1b has operated, and, following the provision of $1 \mathrm{c}$, current speaker has continued, then the rule-set a-c reapplies at the next transition-relevance place, and recursively at each next transition-relevance place, until transfer is effective.

Rules 1a, 1b, and 1c are to be used in this analysis as they are the operational rules applied in conversation. It can be summarized that rule $1 \mathrm{a}$ deals with the 'current speaker selects next', rule $1 \mathrm{~b}$ refers to 'self select', and rule 1c with the 'speaker' continuation'. The followings talk about the three rules of turn taking of marhata in the Batak Toba wedding tradition ceremony.

\subsection{Research Design}

\section{Research Method}

This study is a qualitative descriptive research. According to Berg (1989:2), a qualitative research is a type of research which tries to describe an object. It refers to meaning, concept, definition, language characteristics, metaphor, symbols, and the description of something. The phenomena focussing this research is the conversation structure using conversation analysis by Sack, Schegloff, and Jefferson (1974).

\subsection{The Research Instrument}

Accordingly, the data of this study are the utterances containing turn taking in the conversation of traditional wedding ceremony of Batak Toba using the method of observation; direct, participatory observation or non-participatory observation.

The instrument used is a blackberry mobile and camera digital having the capability to record the data of the conversation. According to Hutchby and Woofitt (1999), the types of the data in a conversation analysis are the recorded interaction to be transcribed.

\subsection{Technique of Data Analysis}

The technique of the data analysis used in this research follows the model used by Miles and Huberman (1984: 23). This model includes three interactive steps, they are: 1. data reduction; 2. data display; and 3. drawing conclusion. The data analysis is done as early as in the beginning of the data collection. During the data collection, the researcher sits at the ceremony following the conversation passively. As the conversations go on, the recordings are controlled as well as some notes about the conversation are taken on a small note. The purpose of this condition is to keep a natural setting for the conversations presented by the Batak Toba speakers.

Besides Miles and Huberman models, the researcher also applied some techniques of conversation analysis proposed by Tannen (2005:160) as followings :

1. Selecting the clearly qualified recording

2. Repeatedly and causioulsy listening

3. Transcribing the conversation by coding the speaker and the numbering the speeches 
4. Segmenting linguistics phenomenon such as turn taking based on the topics of each conversation.

5. Identifying the turn taking

6. Interpreting the findings

7. Concluding the findings

\section{Data Analysis And Interpretation}

\subsection{Turn-Taking of Marhata in Speech Event of Marhusip}

Turn taking of marhata in marhusip speech event applies the three rules in which the first rule comprise of Current Speaker Selects Next Speaker (CSSNS), Next Speaker Selects Current Speaker (NSSCS), and Next Speaker Selects Next Speaker (NSSNS). Each of the rule has different occurrences as tabulated in Table 1.

Table. 1 Turn Allocation Component in Speech Event of Marhusip

\begin{tabular}{|c|c|c|c|c|c|c|c|}
\hline \multirow{3}{*}{ No } & \multirow{3}{*}{ Topics of Marhata } & \multicolumn{5}{|c|}{ Turn Allocation Component } & \multirow{3}{*}{ Total } \\
\hline & & \multicolumn{3}{|c|}{ Rule 1} & \multirow{2}{*}{$\begin{array}{l}\text { Rule } 2 \\
\text { NSC }\end{array}$} & \multirow{2}{*}{$\begin{array}{r}\text { Rule } 3 \\
\text { CSC }\end{array}$} & \\
\hline & & CSSNS & NSSCS & NSSNS & & & \\
\hline 1 & Manise & $\begin{array}{l}1,7,9 \\
11,13\end{array}$ & 6 & $\begin{array}{l}2,3,4 \\
5,14\end{array}$ & - & $8,10,12$ & 14 \\
\hline 2 & $\begin{array}{l}\text { sipasahaton } \\
\text { (sinamot) }\end{array}$ & $\begin{array}{l}1,3,9,11, \\
13,16,18 \\
20,22,24 \\
26,27,28\end{array}$ & $\begin{array}{c}2,4,8,10 \\
17\end{array}$ & $6,7,14$ & 5,9 & $\begin{array}{l}12,15, \\
19,21, \\
23,25\end{array}$ & 28 \\
\hline 3 & sipatupaon di martumpol & 1,3 & $2,4,6$ & - & 5 & 7 & 7 \\
\hline 4 & rencana tanggal martumpol & 1,3 & 2 & - & 4,5 & - & 5 \\
\hline 5 & marsibuha-buhai & $1,5,7$ & $2,4,6,8$ & - & 3 & - & 8 \\
\hline 6 & panggoraan & $1,3,5,7$ & $2,4,6$ & - & - & - & 7 \\
\hline 7 & $\begin{array}{l}\text { pinggan } \\
\text { panganon }\end{array}$ & $1,3,7$ & 2,4 & - & $5,6,8$ & - & 8 \\
\hline 8 & jolma sijouon & $1,5,7$ & & $\begin{array}{l}2,3,10, \\
11,13\end{array}$ & $4,8,12$ & 6,9 & 13 \\
\hline & $\begin{array}{r}\text { Total } \\
\text { Percentage } \\
\end{array}$ & 35 & $\begin{array}{c}19 \\
67(74 \%) \\
\end{array}$ & 13 & $\begin{array}{c}12 \\
12(13 \%) \\
\end{array}$ & $\begin{array}{c}12 \\
12(13 \%) \\
\end{array}$ & \\
\hline
\end{tabular}

As explained above, the theory used to analyze the turn taking is that of Sacks, et.al (1974) stated that turn taking is a process of interaction to participate in interactive activities. The rules of turn taking are analyzed based on the topics found in the conversation. There are eight topics of marhata in the speech event of marhusip.

Topic 1 : Manise 'Whispering'

The data on topic 1 denotes that the conversation is started by the speaker from the woman side (SFWS) as a current speaker. The turn taking begins by selecting the next speaker (village chief). This turn is marked by the use of Batak addresses 'raja dongan sahuta' in the statement of 'Hupasahat hami ma tu hamu raja dongan sahuta nami'. In Batak Toba language dongan sahuta 'group of society in village (GSV)' has a role to converse in every Batak Toba traditions. Then, GSV selects the next speaker (speaker from the man side (SFMS). This turn is stated by using Batak Toba personal pronoun 'hamu' or 'you' to SFMS in command form 'Tangkas ma paboa hamu haroan na uli sibegeon ni sipareon dohot sipeopon ni roha'. SFMS continues the conversation by selecting the GSV using Batak addresses raja nami 'our king' in the statement 'Ianggo haroro nami raja nami tu panggabean parhorasan do raja nami'. Then, GSV continues the conversation selecting SFMS by the address of tutur nami 'our guest' in command 'Ditangkas ni panggabean parhorasan $i$ ba dipatangkas tutur nami ma asa tangkas hubege hami'. Then, SFMS continues the conversation and selects GSV to continue by using address Raja i 'the King' in statement 'Ba adong saotik ulaon pardonganon anak nami, ba ido na naeng sipaboaon tu Raja i'. GSV then continues the conversation by selecting the currenct speaker SFWS using second Batak personal pronoun hamu in statement 'Tarsongoni ma boa-boa ni tutur ta sian Siantar, pinasahat ma tu hamu. The current speaker SFWS continues the conversation to GSV by the second Batak personal pronoun in statement too. 'Jadi boru ni dongan sahuta nami do antong sungkunon nami di jolo ni natorasna'. Then, the current speaker selects the next speaker GSV using adrress raja dongan sahuta 'King in society' in statement 'Olo raja dongan sahuta nami'. GSV continues the conversation in interrogative Didia borunta $i$ ? 'Where is our daughter?' The current speaker SFWS then continues to the next speaker bride (B) using address boru 'daughter' in interrogative. The next speaker GSV continues the conversation without selecting anyone saying iya 'yes'. SFWS selects next speaker SFMS by using second Batak Toba personal pronoun hamu in command 'Tong ma patangkas hamu nang bere nami'. At the end of the conversation, SFMS selects the next speaker bridegroom (BG) by the address of anak nami 'our son' in interrogative Bagaimana dengan mu? 'What do you think?'. SFMS closed the conversation using statement iya 'yes'. 
Turn allocation on topic 1 can be drawn as follows:
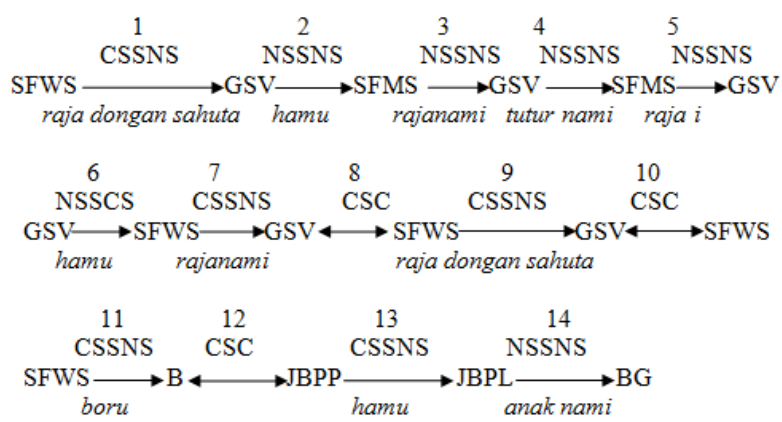

Based on the analysis of turn allocation component on the first topic, it can be seen that there are two rules of turn taking, namely :

1) The first rule: the turn taking is ditermined by selecting the next speaker. This component has three forms, namely:

a) CSSNS (Current Speaker Selects Next Speaker)

b) NSSCS (Next Spekaer Selects Current Speaker)

c) NSSNS (Next Speaker Selects Next Speaker).

Taking turn to the next speaker is marked by using some Batak addresses, such as dongan sahuta from SFWS to GSV; tutur nami and muna from GSV to SFMS; and raja nami from SFMS to SFWS. This is marked by the use of $\longrightarrow$; meaning selecting the next speaker.

2) The third rule; the turn taking is not selected previously and other speaker does not take part to be the next speaker; the current speaker can continue the conversation but he is not obliged to do that. This rule is called current speaker continues (CSC). This is marked by the use of

Topic 4 : Rencana Tanggal Martumpol 'The Date Of Engangement'

The discussion on this topic is began by SPWS as a current speaker and selects the next speaker SFMS using Batak Toba Pronoun hamu 'you'. Then, SFMS selects the current speaker (SFWS) by the address raja $i$ 'the King'. SFWS selects the next speaker SFMS by the address amangboru. Then, GSV and SFMS continue the conversation without any reference.

Turn allocation on topic 4 is drawn as follows:

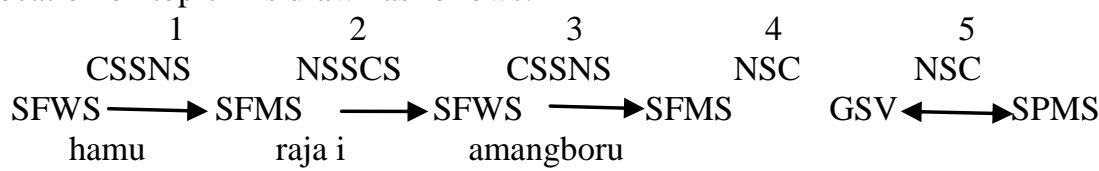

Turn allocation component on the fourth topic consists of two rules, namely :

1) The first rule comprises of three forms; a) CSSNS, b) NSSCS, and c) NSSNS. The reference to the next speaker is signed by the use of Batak addresses, namely amangboru and hamu from SFWS to SFMS, rajanami from SFMS to SFWS, raja bolon from SFMS to GSV, hamuna from GSV to SFMS

2) The second rule: The next speaker continues (NSC). 
4.2 Turn-Taking of Marhata in Speech Event of Marpudunsaut

Table 2. Turn Allocation Component in Speech Event of Marpudunsaut

\begin{tabular}{|c|c|c|c|c|c|c|c|}
\hline \multirow{3}{*}{ No } & \multirow{3}{*}{ Topics of Marhata } & \multicolumn{5}{|c|}{ Turn Allocation Component } & \multirow{3}{*}{ Tota } \\
\hline & & & Rule 1 & & Rule 2 & Rule 3 & \\
\hline & & CSSNS & NSSCS & NSSNS & $\mathrm{NSC}$ & $\mathrm{CsC}$ & \\
\hline 1 & tudu-tudu sipanganon & $\begin{array}{c}1,3,5,9, \\
13,15,19\end{array}$ & $\begin{array}{c}2,10,12 \\
14,16\end{array}$ & - & $7,11,17$ & $\begin{array}{c}4,6,8 \\
18\end{array}$ & 19 \\
\hline 2 & barita ni sipanganon & 1,3 & 2,4 & - & - & - & 4 \\
\hline 3 & somba ni uhum (sinamot) & $\begin{array}{c}1,3,5,15 \\
19,22,27,29\end{array}$ & $\begin{array}{c}2,4,14 \\
18,26,28 \\
32\end{array}$ & $\begin{array}{c}6,8,10, \\
12,20,21 \\
23,24,30\end{array}$ & $\begin{array}{c}7,9,11,13 \\
17,25,31\end{array}$ & 16 & 32 \\
\hline 4 & pangidoan ulos & 1,3 & 2 & - & - & - & 3 \\
\hline 5 & sangkap dohot rencana & $\begin{array}{c}1,3,5,9 \\
11,13,15 \\
21,25\end{array}$ & $\begin{array}{c}2,4,6,8 \\
10,16,22 \\
24,26\end{array}$ & - & $\begin{array}{c}7,17,19,23, \\
27\end{array}$ & $\begin{array}{l}12,14, \\
18,20\end{array}$ & 27 \\
\hline 6 & Parsuhion & $1,5,7$ & $2,6,8$ & 3 & - & 4,9 & 9 \\
\hline 7 & patortor parumaen & 1. & 7 & 3.5 & 2.4 .6 .8 .9 & - & 9 \\
\hline 8 & Marsarapan & 1,3 & 2,4 & - & - & - & 4 \\
\hline 9 & Panandaion & $1,5,7$ & 4,6 & 2 & 3 & & 7 \\
\hline 10 & ingot-ingot & $1,3,7$ & 2,4 , & $8,10,12$ & $\begin{array}{c}5,9,11, \\
13\end{array}$ & 6 & 13 \\
\hline 11 & paulak une & - & 3 & - & 1,2 & - & 3 \\
\hline & $\begin{array}{r}\text { Total } \\
\text { Percentage }\end{array}$ & 40 & $\begin{array}{c}35 \\
91(70 \%)\end{array}$ & 16 & $\begin{array}{c}27 \\
27(21 \%)\end{array}$ & $\begin{array}{c}12 \\
12(90)\end{array}$ & \\
\hline
\end{tabular}

4.3 Turn-Taking of Marhata in Speech Event of Marunjuk

Table 3. Turn Allocation Component in Speech Event of Marunjuk

\begin{tabular}{|c|c|c|c|c|c|c|c|}
\hline \multirow{3}{*}{ No } & \multirow{3}{*}{ Topics of Marhata } & \multicolumn{5}{|c|}{ Turn Allocation Component } & \multirow{3}{*}{ Total } \\
\hline & & & Rule 1 & & Rule 2 & Rule 3 & \\
\hline & & CSSNS & NSSCS & NSSNS & NSC & & \\
\hline 1 & pinggan panungkunan & $1,5,9$ & $2,4,6,8,10$ & - & 3,7 & - & 10 \\
\hline 2 & pasahathon adat na gok & $1,3,5,7,9,11$ & $\begin{array}{c}2,4,6,8 \\
10,12\end{array}$ & - & - & - & 12 \\
\hline 3 & Panandaion & $\begin{array}{c}1,6,12,21 \\
27,31,33 \\
44,46\end{array}$ & $\begin{array}{c}9,11,13 \\
20,22,24 \\
26,30,32 \\
37,43,45 \\
47,49\end{array}$ & $\begin{array}{c}2,7,15 \\
17,19, \\
28,34 \\
35,39,40 \\
41,42\end{array}$ & $\begin{array}{l}3,4,8,10, \\
14,16,18 \\
23,25,29 \\
36,38,48\end{array}$ & - & 49 \\
\hline 4 & tintin marangkup & 1 & 6 & - & 2,4 & 3,5 & 6 \\
\hline 5 & ulos tongos sadari & $\begin{array}{c}1,3,5,7,9,11 \\
13,15\end{array}$ & $\begin{array}{c}2,4,6,10 \\
12,14,20 \\
28,32\end{array}$ & & $\begin{array}{l}17,19,21,23 \\
25,27,29,31 \\
33,34\end{array}$ & $\begin{array}{l}8,16,18 \\
22,24,26\end{array}$ & 34 \\
\hline & & & 28,32 & & 33,34 & 30 & \\
\hline 6 & olop-olop & 1,3 & $2^{2}$ & $4,7,8$ & $5,6,9$ & - & 9 \\
\hline 7 & $\begin{array}{l}\text { paulak une } \\
\text { tingkir tangog }\end{array}$ & $\begin{array}{l}1,3,5 \\
1,5\end{array}$ & $\begin{array}{c}2,4,6,8 \\
6\end{array}$ & & 7 & - & $\begin{array}{l}8 \\
6\end{array}$ \\
\hline 8 & $\begin{array}{l}\text { tingkir tangga } \\
\text { mangaтри }\end{array}$ & 1,5 & 6 & - & 3 & $\begin{array}{c}2,4 \\
-\end{array}$ & 1 \\
\hline 9 & $\begin{array}{r}\text { mangampu } \\
\\
\begin{array}{r}\text { Total } \\
\text { Percentage }\end{array}\end{array}$ & $\begin{array}{c}1 \\
35\end{array}$ & $\begin{array}{c}41 \\
41 \\
91(67 \%)\end{array}$ & 15 & $\begin{array}{c}32 \\
32(24 \%)\end{array}$ & $\begin{array}{c}11 \\
12(9 \%)\end{array}$ & \\
\hline
\end{tabular}

Based on the analysis of turn taking of in the three speech events of Batak Toba traditional wedding ceremony, turn taking in marhata among the speakers is applied by following the rules of turn taking as tabulated in this following table.

Table 4. Turn Taking of Marhata in Batak Toba Traditional Wedding Ceremony

\begin{tabular}{lccc}
\hline \multicolumn{1}{c}{ Speech Events } & $\begin{array}{c}\text { Turn Allocation Component } \\
\text { Rule 1 }\end{array}$ & $\begin{array}{c}\text { Rule 2 } \\
\text { (NSC) }\end{array}$ & $\begin{array}{c}\text { Rule 3 } \\
\text { (CSC) }\end{array}$ \\
\hline Marhusip & $74 \%$ & $13 \%$ & $13 \%$ \\
Marpudunsaut & $70 \%$ & $21 \%$ & $9 \%$ \\
Marunjuk & $67 \%$ & $24 \%$ & $9 \%$ \\
\hline
\end{tabular}

In every speech event of marhata, the first rule of turn taking occurs more dominantly $(74 \%, 70 \%$, and $67 \%$ ) which shows that the current speaker takes turn as the next speaker selects next, the next speaker takes turn as the current speaker takes turn, and next speaker takes turn as next speakers selects. The dominant turn allocation is in the speech event of marhusip. The second rule of turn taking is more dominant at speech events of marpudunsaut and marunjuk.

The three rules of turn taking are applicable in marhata on every speech events of Batak Toba traditional wedding ceremony, namely, the speaker selects the next speaker, the next speaker continues, and the current speaker continues. The first rule comprises of three forms of turn taking, namely the current speaker selects the next speaker (CSSNS), the next speaker selects the current speaker (NSSCS), and the next speaker selects the next speaker (NSSNS). CSSNS or NSSCS are the speaker from the woman side (SFWS) or the speaker from the man side (SFMS). On the other hand, NSSNS are those out of the two speakers.

The first rule, the speaker selects the next speaker, is the most dominantly used in marhata. It implies that in marhata of Batak Toba traditional wedding ceremony, it can be concluded that there is no interruption or the turn taking is bounded culturally by the use of kinship based on Dalihan Na Tolu (DNT) 'the three culture 
pillars of the Batak Toba Society. The existence of references in turn taking shows the minimum or absence of gap or errors in turn taking.

The kinship system becomes the phenomena in turn taking in marhata on the Batak Toba traditional wedding ceremony. The references found in every event of marhata apply the kinship system relating to DNT. Furthermore, the reference of turn taking is marked by the use of Batak Toba Pronoun, especially the second pronoun hamu' you' and plural pronoun hita 'we'.

The meaning of kinship system found in this research is not the same when used in the daily context. For example, when a Batak Toba calls tulang 'uncle' to someone he has just recognized; the meaning is not the same with address tulang when someone says it while the process of marhata is going on. The first address can be said by anyone who likes to call 'tulang', but the second one, the address is given to the proper person who takes role as tulang. Furthermore, this kinship system becomes the distinguishing with the other kinship system. When someone speaks using the address Ibu and Bapak in Indonesian, they can contain some meanings; it can be an address to a teacher, address to old people to the young as an honour.

In introducing the topics, SFWS participates more dominantly in the speech event of marhusip and marpudunsaut. The two speech events are held in the woman's side in Medan. SFWS is the speaker who has power in conducting the process of marhata from the beginning until the end of the conversation; the one who determines who speaks next. On the other hand, the speech event of marunjuk was held in Pematangsiantar. The topics of conversation are more dominantly introduced by SFMS and he is the one who has power to manage the process of conversation from the beginning until the end of the conversation. This condition is supported by Short (1996: 206-7) stating "The behaviour of a participant at a TRP is closely associated with power: "powerful speakers in conversations have the most turns, have the longest turns, initiate conversational exchanges, control what is talked about and who talks when, and interrupt others".

SFWS and SFMS are the speakers who have the most turns and they are called raja parhata 'the king of speakers' who have power to conduct and control the process of conversation.

\section{Conclusions}

The three rules of turn allocation are applicable in the conversation of Batak Toba traditional wedding ceremony. The most dominant rule is the first rule by selecting the speaker with three variations, namely current speaker select next speaker, next speaker selects current speaker, and next speaker selects next speaker. Not all the speakers have the same turn allocation. In every event of marhata, the first rule has the most turn allocation. It means that the speaker from the woman's side starting marhata has the most power in turn taking. In time of continuing the conversation, the current speaker always selects the next speaker using Batak addresses, such as Rajanami, hula-hula nami, and Raja Bolon from SFMS to SFWS; amangboru is an address of SFWS to SFMS; anggidoli an address from the first level of surname (higher) to the lower; hahadoli from the lower level to the higher. This is a custom in any interaction of Batak Toba culture in the speaking politeness. Sometimes, the next speaker continuing the conversation is not selected by the current speaker, but based on the content of his utterances, the competent speaker can continue or respond the conversation. From the three rules of turn taking, the first rule in every speech event shows the highest number and the difference with the second and the third rule is high enough. Thus, it can be concluded that in marhata on every Batak Toba traditional wedding ceremony, the turn taking is significantly influenced by Batak Toba culture, where the system of kinship plays the most important role in every turn taking. Overlapping and interruption do not exist in marhata. It denotes that the social relation among the Batak Toba society is truly reflected and set in DNT. The Batak Toba characteristics lie on the DNT. If someone is involved in the social interaction, he will not release from the social position called dalihan natolu, namely dongan sabutuha 'friends in the same surname', hula-hula 'people from the woman side', and boru 'daughers'. Thus, it can be said that turn taking in marhata is tightly performed in the sequeunce of SFWS to SFMS or SFMS to SFWS.

\section{References}

[1] Berg, Bruce L. (1989). Qualitative research methods. Boston: Allyn and Bacon.

[2] Carbaugh, Donald. (2005). Cultures in conversation. London: Lawrence Erllllbalum Associates.

[3] Hutchby, I., and Wooffitt, R. (1998). Conversation analysis. London: Polity Press.

[4] Miles, M. B. and Huberman, A.M. (1988). Qualitative data analysis. London: Sage Publication.

[5] Reisman, K. (1974). Contrapuntal conversations in an Antiguan village. In Bauman, R. and Sherzer, J. (eds.) Explorations in the ethnography of speaking. Cambridge: Cambridge University Press.

[6] Sacks, et al. (1974). A simplest systematics for the organization of turn-taking for conversation. Language 50 696-735.

[7] Sacks, Harvey. (1978). A simplest systematics for the organization of turn-taking for conversation. In J.N Schenkein (ed.), Studies in the organization of conversational interaction, 07-55. New York: Academic Press.

[8] Schegloff, E. A. (1977). On some questions and ambiguities in conversation. In W. Dressler (Ed.), Current Trends in Textlinguistics, pp. 81-102. Berlin: Mouton De Gruyter.

[9] Schegloff, E. A. (2007). Sequence Organization in Interaction: A Primer in Conversation Analyis, Volume 1 Cambridge: Cambridge University Press.

[10] Short, M. (1996). Exploring the Language of Plays, Poems and Prose. Essex: Longman.

[11] Tannen, Deborah. (2005). Conversational Style: Analysis Talk Among Friends. New Jersey: Alex Publishing Corporation Norwood. 